\title{
Tinjauan Mobile Government Dalam Pemanfaatan Peluang Digital di Provinsi Jawa Barat
}

\author{
Muhammad Febriansyah Rohimat' \\ ${ }^{1}$ Program Studi Administrasi Publik, Fakultas Ilmu Sosial dan Ilmu Politik. UIN Sunan \\ Gunung Djati Bandung, Bandung.
}

\begin{abstract}
Globalization as the estuary of cultural changes and values in society brings drastic transformations. The use of mobile phones and the internet which are increasing every year also requires the government to be able to give innovation to the concept of public services that are integrated with technological changes that are currently happening. The Mobile government which is part of e-government is a concept that should be implemented by the government. The West Java Provincial Government as one of the components of government in Indonesia in taking advantage of these opportunities adapts to technology. Adapting technology as part of government governance is the main focus on implementing mobile government, especially on mobile applications to achieve equitable and integrated public services. The purpose of this study is to analyze the optimization of digital opportunities in West Java Province with the concept of mobile government as the basis for its application. This research is classified as descriptive qualitative. The results show that mobile government has been implemented in the public service process carried out by the West Java Provincial Government. The purpose of this study is to analyze the optimization of digital opportunities in West Java Province with the concept of mobile government as the basis for its application. This research is classified as descriptive qualitative. The results show that mobile government has been implemented in the public service process carried out by the West Java Provincial Government such as Pikobar, Sapawarga, K-MOB, Si Votun Jabar, and Sambara applications.
\end{abstract}

Keywords: Mobile Government, Digital, Public Service

\section{Pendahuluan}

Pesatnya perkembangan teknologi dewasa ini telah membawa perubahan secara dramatis terhadap mindset dan cultural set masyarakat dunia. Globalisasi sebagai muara perubahan membawa beragam arus nilai dan budaya baru terhadap aspek kehidupan seperti identitas, pemahaman, pola komsusi, waktu, keterampilan, berkomunikasi, berpikir, dan bertindak mengalami modifikasi dan akulturasi dengan budaya lokal (Savitri, 2019).
Pengaruh ini-pun berdampak pada pemenuhan kebutuhan masyarakat. Pemerintah sebagai pelayan publik dituntut untuk menjadi aparatur madani dengan penerapan teknologi sebagai garda depan pada proses pelayanan publik.

Pengintegrasian pelayanan publik dengan teknologi diupayakan untuk mencapai tata kelola pemerintahan yang baik atau good governance. EGovernment sebagai sarana pengintegrasian teknologi dengan tata kelola kepemerintahan telah 
dilaksanakan di Indonesia sejak tahun 2000 (Hadiana \& Renaldi, 2018). Maraknya korupsi, kolusi, dan nepotisme melatarbelakangi penerapan E-Government. Dimulai dari serentaknya pemerintah pusat dan daerah yang membentuk website dan peningkatan intensitas publikasi via media massa sebagai bentuk transparansi.

Persatuan Bangsa-Bangsa (PBB) mengemukakan lima tahap dalam pengklasifikasian e-government. Pertama, emerging presence ditandai dengan tersedianya situs web resmi pemerintah yang menjadikan informasi yang bersifat fundamental, memiliki batasan, dan cenderung stagnan. Kedua, enhanced presesnce merupakan tahap dimana situs web pemerintah telah menyediakan informasi yang lebih komprehensif seperti regulasi dan laporan pemerintah. Lalu terdapat site map dan situs web yang dapat ditemukan oleh masyarakat melalui perangkat elektroniknya. Ketiga, interactive presence sebagai tahap dimana pemerintah menyediakan formulir dan keperluan data yang dapat diunggah. Selain itu, masyarakat memiliki akses dan dapat menghubungi pejabat pemerintah. Keempat, transactional presence ditandai dengan hadirnya situs web pemerintah yang dapat menjadi sarana transaksi baik itu finansial maupun non-finansial selama 24 jam. Kelima, networked presence merupakan tahap terakhir daripada kesiapan e-government yang ditandai dengan tersedianya pelayanan dua arah dan transparansi segala kegiatan pemerintah yang terus dilaksanakan pembaharuan secara berkala (United Nations, 2005).

United Nations (UN) eGovernment Survey merilis data terkait penerapan e-government di dunia pada tahun 2020. Dari data tersebut dilaporkan bahwa Indonesia menunjukkan perkembangan yang positif, hal ini dibuktikan dengan naiknya peringkat Indonesia dari urutan 107 pada tahun 2018 menjadi urutan 88 pada tahun 2020 (menpan.go.id, 2020) Namun, saat ini Indonesia dihadapkan dengan digital divide pada beberapa daerah seperti Kota Surabaya dengan Kabupaten Deli Serdang. Lalu, penerapan $e$ government di pulau Jawa cenderung lebih dominan dan maju dibanding dengan provinsi luar jawa (Febriani, 2016). Sinergitas beragam stakeholders diperlukan dalam membangun budaya pemerintahan madani karena penerapan digitalisasi dapat meningkatkan kualitas pelayanan publik (Hardi \& Gohwong, 2020). Supriyatna mengemukakan bahwa masyarakat saat ini membutuhkan pelayanan publik yang responsive, cepat, ekonomis, dan memiliki kepastian hukum (Anggara, 2016).

Disisi lain, terdapat publikasi mengenai jumlah pengguna internet di Indonesia yang dirlis oleh We Are Social mennyentuh angka 175,4 juta pengguna. Terjadi kenaikan sebesar $17 \%$ dan jika dikalkulasikan maka diperoleh angka 25 juta kenaikan pengguna internet dibanding tahun 2019 (Haryanto, 2020). Kementerian Komunikasi dan Informatika Republik Indonesia pada tahun 2017 mengadakan survey dan diperoleh hasil $66,3 \%$ masyarakat Indonesia memiliki smarthphone (Indonesiabaik.id, 2018) Kebutuhan akan gadget yang kian meningkat tiap tahunnya memberikan sinyal positif akan inovasi pelayanan public.

Sudah sepatutnya jika pemerintah mengambil peluang dalam 
optimalisasi pelayanan public melalui perangkat digital. Mobile government sebagai bagian dari realisasi $e$ government (Goyal \& Seema, 2012) dapat menjadi dobrakan dalam pelayanan publick. Kuschu \& Kuschu mengemukakan bahwa mobile government diartikan sebagai pemanfaatan beragam teknologi aplikasi, nirkabel, layanan, mobile, dan peralatan untuk meningkatkan kinerja dari pemerintah, warga negara, dan pengusaha (Hadiana \& Renaldi, 2018).

Dalam pengoptimalan peluang yang tersedia, Pemerintah Provinsi Jawa Barat menerapkan pelayanan public berbasis aplikasi. Sebagai contoh pada awal pandemic covid-19 dimana masyarakat mengonsumsi derasnya arus informasi yang tidak disaring secara seksama menimbulkan resiko miskonsepsi. Untuk mencegah hal tersebut kian meningkat, maka Pemerintah Provinsi Jawa Barat meluncurkan aplikasi PIKOBAR (Pusat Informasi dan Koordinasi COVID-19 Jawa Barat) pada Jumat, 30 Maret 2020 (Hermansyah, 2020)

Selain itu, terdapat mobile service lainnya dalam mendukung pelaksanaan mobile government yang dilakukan oleh Pemerintah Provinsi Jawa Barat, seperti pembuatan aplikasi KMOB JABAR, SI VOTUN JABAR, Sapawarga, dan SAMBARA. Inovasi tersebut lahir daripada karakteristik masyarakat dewasa ini yang cenderung kompleks, beranekaragam, dan dinamika yang unik (Anggara, 2016). Seakan stigma masyarakat terhadap pemerintah yang dianggap kurang efisien dan tertinggal jauh dibanding sektor swasta mulai tergerus dengan nilainilai positif (Mardiasmo, 2018).
Selanjutnya, novelty atau yang membedakan penelitian yang dilakukan dengan penelitian terdahulu adalah dalam penelitian iini penulis mengugnakan konsep mobile government. Selain itu, peneliti melakukan analisis pada aplikasi yang dikeluarkan oleh Pemerintah Provinsi Jawa Barat dalam proses pelayan publik. Sehingga hasil akhir penelitian akhir yan gpenulis lakukan akan menghasilkan analisis mengenai pengoptimalan mobile government $\mathrm{di}$ Provinsi Jawa Barat.

Maka dari itu peneliti tertarik untuk mendalami bagaimana pengoptimalan potensi digital di Provinsi Jawa Barat yang dikorelasikan dengan pelaksanaan mobile government. Dengan judul penelitian Tinjauan Mobile Government Dalam Pemanfaatan Peluang Digital di Provinsi Jawa Barat. Adapun tujuan daripada penelitian yang hendak diperoleh adalah untuk menganalisis pemanfaatan peluang digital dengan konsep mobile government berdasarkan konteks penerapan pada Provinsi Jawa Barat oleh pemerintah daerah.

\section{Metode Penelitian}

Peneliti menggunakan metode deskriptif dengan pendekatan kualitatif seperti yang dikemukakan oleh Miles dan Huberman. Penelitian deskriptif kualitatif ini digunakan karena peneliti menilai hal tersebut relevan dengan permasalahan yang terjadi dan selaras dengan tujuan penelitian yakni untuk memberikan deskripsi atas pemanfaatan peluang digital dengan konsep mobile government dalam konteks penerapan di Provinsi Jawa Barat. Adapun teknik pengumpulan data diperoleh melalui studi literatur 
dengean menekankan pada penghimpunan informasi darai bacaan atau sumber refernsi yang relevan, mencatan, dan mengolah untuk data paelitian secara ilmiah untuk mencapai tujuan penelitian. Teknik analisis data dilakukan menggunakan teknik analisis yang dikemukakan oleh Miles dan Huberman, yakni reduksi data, display data, dan conclusion drawing.

\section{Hasil dan Pembahasan}

Mobile government dengan ciri khas aksesibilitas tinggi terhadap masyarakat yang tidak terbatas oleh kondisi geografis dan waktu dapat menyediakan komunikasi yang holistik dengan para stakeholder (Abu Tair \& Abu-Shanab, 2014). Mobile government merupakan rangkaian pelaksanaan daripada E-government. Secara singkat e-government terdiri atas tiga tahapan, yaitu publish, interact, dan transact. Inti dari ketiga tahapan e-government tersebut adalah transparansi tata kelola pemerintahan untuk mewujudkan kepercayaan public yang tinggi dengan menyediakan wadah untuk berinteraksi sebagai wujud akuntabilitas.

Good governance yang menjadi kiblat dalam melaksanakan tata kelola pemerintahan yang terdiri dari sepuluh karakteristik, yaitu 1) Participation, 2) Rule of Law, 3) Transparency, 4) Responsiveness, 5) Consesnsus orientation, 6) Equity, 7) Effectiveness and efficienscy, 8) Accountability, 9) Strategic vision, 10) Interrelated (Handayani \& Nur, 2019) dipadupadankan dengan konsep penerapan mobile government. Kunshchu mengemukakan bahwa strategi penerapan mobile government menjadi konsep yang saling melengkapi yang dapat meningkatkan pelayanan pada masyarakat luas, pelaku bisnis, dan pemerintahan (Abu Tair \& AbuShanab, 2014).

Kebutuhan terhadap mobile government menjadi suatu keniscayaan pada abad 21 dengan beragam perkembangan teknologi yang saat ini terjadi. Ditambah dengan terintegrasinya segala perangkat yang dimiliki masyarakat terhadap internet atau lebih dikenal dengan Internet of Thingsi (IoT). Secara sederhana, IoT dapat diartikan sebagai konsep yang menghubungkan perangkat elektronik apapun seperti ponsel, laptop, tv, dan perangkat lainnya yang memiliki tombol aktif dan non-aktif terhadap internet. Pengintegrasian ini memiliki keterkaitan dengan konsep Smart City.

Smart City merupakan kondisi dimana suatu teritori wilayah mengedepankan penggunaan teknologi dalam urusan-urusan public yang berpengaruh positif pada kehidupan masyarakat. Penggunaan teknologi yang dimaksud adalah penerapan internet of things, smart agriculture, smart home, pendidikan, smart government, open data, smart retail, smart mobility, smart health, dan smart energy (Savitri, 2019). Smart government sebagai salah satu penopang pada smart city dapat ditinjau daripada penerapan mobile government sebagai basis dalam pelaksanaan pelayanan publik. Selain itu dengan tingginya jumlah pengguna ponsel, dimilikinya perangkat dengan mobilitas tinggi, dapat berjalan tanpa batas jarak, tidak memakan biaya yang besar, dan kemudahan dalam penggunaanya menjadi dorongan transformasi pemerintah pada mobile government. 
Penerapan mobile government dapat dilihat pada inovasi-inovasi yang dilakukan oleh Pemerintah Provinsi Jawa Barat. Peneliti menemukan beberapa mobile application yang dipublikasikan via android dan apple operating system seperti PIKOBAR, Sapawarga, KMOB Jawa Barat, Si Votun Jabar, dan Sambara. Peruntukkan aplikasi tersebut ditujukan untuk memudahkan proses pelayanan publik dan memaksimalkan kinerja birokrasi. Dengan jumlah penduduk 48,27 juta jiwa dengan persentase prnduduk usia produktif (15-64 tahun) berkisar 70,68\% (BPS, 2020) menjadi peluang dan tantangan bagi Pemerintah Provinsi Jawa Barat. Adapun penjelasan mengenai kelima aplikasi tersebut, sebagai berikut:

\section{PIKOBAR}

Wabah Pandemi Covid-19 yang kian meningkat tiap harinya di Provinsi Jawa Barat menimbulkan kekhawatiran bagi masyarakat dan pemerintah. Upaya sosialisasi kian massif dilakukan agar mengedukasi warga Jawa Barat mengenai protocol kesehatan, social distancing, dan kebijakan-kebijakan preventif pemerintah lainnya. Ridwan Kamil selaku Gubernur Jawa Barat melakukan optimalisasi dan pemangkasan alur pelayanan public agar dapat tersampaikdan dengan merata melalui pemanfaatan teknologi. Berawal dari situsweb pikobar.jabarprov.go.id, kini merambah pada mobile apps yang dapat diunduh di beragam platform. Fokus daripada aplikasi PIKOBAR ini untuk memberikan segala informasi secara satu pintu sehingga masyarakat tidak kebingungan untuk memperoleh informasi valid. Terdapat beberapa keunggulan daripada peluncuran aplikasi PIKOBAR, yaitu (1) Mencegah dan menekan informasi yang tidak valid mengenai Covid-19. (2) Melakukan update secara berkala mengenai total kasus terkonfirmasi, pasien dirawat, pasien sembuh, dan pasien meninggal. (3) Masyarakat dapat menghubungi nomor layanan yang disediakan oleh Pemerintah Provinsi Jawa Barat yaitu di nomor 119 atau 085697391854. (4) Penyampaian informasi dengan menggunakan infografis dan material-material yang menarik dalam aspek desain. (5) Terdapat fitur untuk memberikan keluhan dan saran terkait penanganan Covid-19. (6) Dapat mendaftar dan melihat terkait program bantuan sosial yang dirancang untuk mendukung kesejahteraan masyarakat. (7) Pengguna dapat menggunakan layanan lapor mandiri dan periksa mandiri terkait Covid-19. (8) Pemerintah Provinsi Jawa Barat dalam rangka meningkatkan kinerja aparatur melakukan survei secara berkala terkait penanganan pandemi Covid-19.

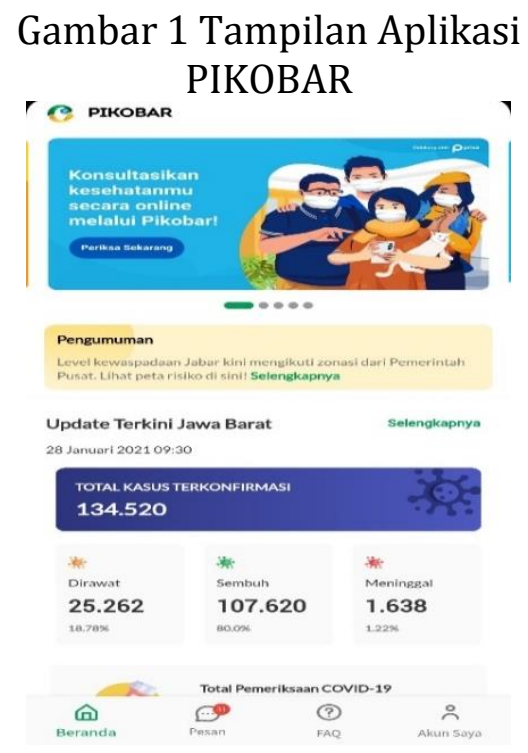

Sumber: Aplikasi PIKOBAR 
Kelebihan yang dimiliki aplikasi PIKOBAR merepresentasikan terbentuknya suatu kultural mobile communication antara pemerintah dan masyarakat. Hal ini dapat dilihat daripada fitur-fitur yang mendorong terjadinya komunikasi dua arah. Ashaari mengemukakan bahwa mobile communication ditandai dengan terjadinya peningkatan saluran dan wadah komunikasi antara pemerintah dan masyarakat yang umumnya dikenal sebagai Governmet to Citizen (G2C) dan Citizen to Government (C2G) (Abu Tair \& Abu-Shanab, 2014).

2. Sapawarga Jawa Barat memiliki 58.720 Rukun Warga (RW) berdasarkan data Dukcapil (Dinas Kependudukan dan Catatan Sipil) tahun 2018 (Pamungkas, 2020), unit terkecil daripada pemerintahan ini memiliki potensi untuk menyukseskan kebijakan pemerintah. Sinergitas dan budaya gotong royong tiap perangkat daerah mulai dari pemerintah pusat, pemerintah daerah, hingga pada unit RT dan RW menjadi suatu keharusan dalam pelaksanaan tata kelola negara. Pemerintah Provinsi Jawa Barat melihat peluang tersebut dan membentuk mobile apps yang dinamakan Sapawarga.
Gambar 2 Tampilan Aplikasi Sapawarga

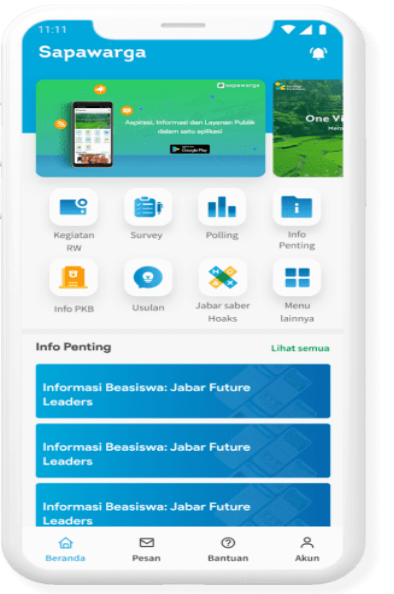

Sumber: Aplikasi Sapawarga

Sapawarga merupakan platform aplikasi untuk meudahkan warga Jawa Barat dalam menyampaikan aspirasi, memperoleh informasi valid, dan mendapat layanan publik yang prima. Aplikasi Sapawarga diresmikan Gubernur Jawa Barat Ridwan Kamil pada tahun 2019. Fitur yang dimiliki aplikasi Sapawarga, yaitu: (1) Kegiatan RW, fitur ini bertujuan agar para ketua RW dapat melaporkan kegiatan yang telah dilakukan dengan melakukan posting kegiatan. (2) Usulan, fitur untuk menyampaikan aspirasi daripada warga Jawa Barat baik berupa saran, keluhan, dan ide yang nantinya akan dikoordinir oleh Pemerintah Provinsi Jawa Barat. (3) Survei, fitur dengan fungsi agar masyarakat dapat memberikan pendapat mengenai program-program yang akan dilaksanakan oleh pemerintah. (4) Polling, fitur yang mengarahkan warga Jawa Barat melakukan voting terkait program-program pemerintah. (5) Nomor Penting, fitur yang menyediakan beragam nomor layanan daripada instansi pemerintah seperti Satpol PP, Kantor Polisi, Call Center Pemerintah Kota, dan 
perangkat daerah lainnya. (6) Info Penting, fitur ini berisikan inforamsiinformasi mengenai bencana alam, kesehatan, pendidikan, beasiswa, pekerjaan, dan lainnya yang dapat diapstikan kebenarannya. (7) Administrasi, fitur yang bertujuan untuk memudahkan masyarakat mendapatkan pelayanan dengan memberikan seluruh informasi seputar persyaratan pelayanan public seperti KTP-el, Kartu Keluarga, Akta Kelahiran, SKCK, Pajak, dan pelayanan lainnya.

\section{K-MOB}

Selain aplikasi yang ditujukan untuk masyarakat umum, Pemerintah Provinsi Jawa Barat merilis Aplikasi Sasaran Kinerja Pegawai (SKP) K-Mob sebagai sarana penilaian aparatur sipil negara. Landasan daripada penilaian ini mengacu pada Pergub No.75 Tahun 2019 yang menilai ASN dari aktivitas, output, dan perilaku. Dalam aspek perilaku, K-Mob merupakan aplikasi yang digunakan oleh ASN di Provinsi Jawa Barat dalam melakukan presensi kehadiran, maka salah satu kriteria penilaian daripada perilaku tersebut yaitu melalui absensi. Tiap ASN yang melakukan aktivitas dan melaporkan kinerja harian, namun tidak mengisi presensi kehadiran maka dianggap tidak tercatat. Penggunaan sistem presensi menggunakan teknologi merupakan suatu inovasi yang dapat mengantarkan ASN pada salah satu indicator terbentuknya smart city, yaitu Smart Government.
Gambar 3 Tampilan Aplikasi

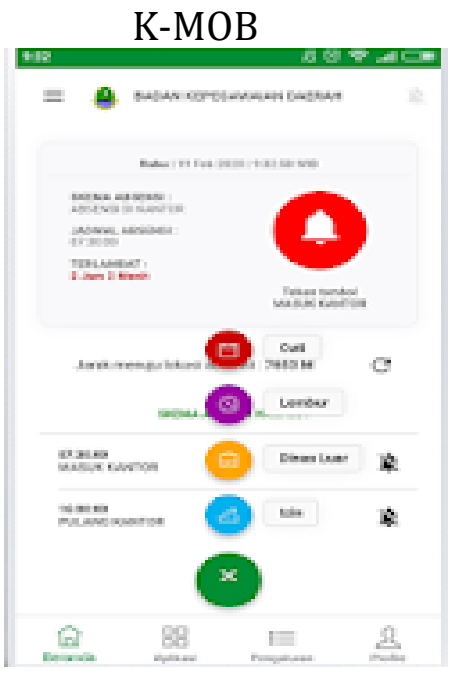

Sumber: Aplikasi K-MOB

4. Si Votun Jabar

Tingginya warga Jawa Barat yang merupakan penyandang tunanetra memerlukan perhatian khusus daripada pemerintah. Terdapat 430 ribu warga atau setara 1,5\% penduduk di Indonesia penyandang tuna netra di Jawa Barat. Keterbatasan fisik tunanetra menghambat terhubungnya mereka dengan dunia luar seperti akses informasi (Pratama et al., 2016). Dalam menyelesaikan permasalahan tersebut, Pemerintah Provinsi Jawa Barat selain mengeluarkan kebijakan dalam bidang kesehatan juga membuat suatu inovasi yang dapat membantu para tunanetra agar mendapatkan inforamsi public. Melalui aplikasi Si Votun Jabar yang dirancang dan dibangun oleh Diskominfo Jabar (Dinas Komunikasi dan Informatika). Mobile apps dengan basis suara sebagai pengaplikasiannya. Kepala Seksi Komunikasi Publik Diskominfo Jabar Indah Dwianti mengatakan bahwa user yang merupakan tunanetra menggunakan Si Votun Jabar melalui suara, sebagai contoh jika 
menanyakan mengenai penanganan Covid-19. Maka operator akan menjawab pertanyaan yang diajukan dengan menghubungi ulang sang penanya. Aplikasi ini telah diujicoba pada SLB Pajajaran dan Wyata Guna (Jabarprov.go.id, 2021). Adapun kepanjangan dari Si Votun Jabar adalah Sistem Informasi Voice Over Tunanetra Jawa Barat dengan dua fitur unggulan, yaitu permohonan informasi dan kritik serta saran.

Gambar 4 Tampilan Aplikasi Si Votun Jabar
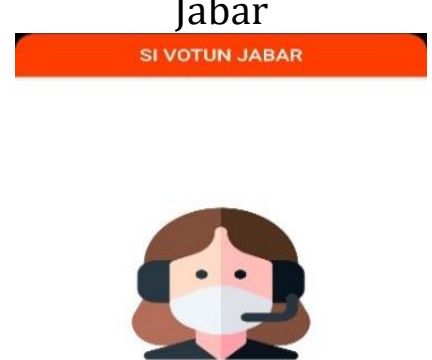

Sumber: Aplikasi Si Votun Jabar

\section{Sambara}

Badan Pendapatan Daerah (Bapenda) Jawa Barat merilis suatu aplikasi yang dinamakan Sambara. Sambara merupakan singkatan dari Samsat Mobile Jawa Barat yang didasari atas tuntutan pelayanan public yang perlu mencapai customer satisfaction. Bapenda berkolaborasi dengan Kepolisian dan Jasa Raharja dalam membuat aplikasi Sambara agar terciptanya keterpaduan dan kohesivitas antara tiap bagian. Stigma masyarakat yang memandang negatif akan pembayaran pajak kendaraan seperti prosedur yang rumit dan proses pelayanan yang memakan waktu dapat terkikis dengan sendirinya dikarenakan aplikasi Sambara. Mudahnya proses pembayaran pajak dapat menjadi daya Tarik utama, sebagai contoh para pemilik kendaraan yang hendak membayar pajak, hanya memasukkan nomor polisi, NIK, dan 5 digit terakhir nomor rangka. Lalu, aplikasi Sambara akan menunjukkan total tagihan pembayaran bersamaan dengan pemberian kode bayar. Selanjutnya, pembayar pajak dapat melakukan pembayaran melalui beragam platform dengan menggunakan kode bayar tersebut. Selain itu, tujuan daripada dibentuknya aplikasi Bapenda diperuntukkan untuk mendongkrak pertumbuhan pembayaran pajak kendaraan.

Gambar 5 Tampilan Aplikasi Sambara

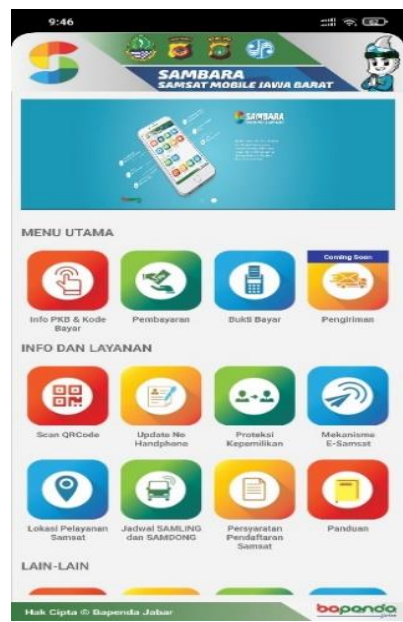

Sumber: Aplikasi Sambara

Kelima aplikasi yang dirilis oleh Pemerintah Provinsi Jawa Barat menunjukkan keseriusan pemerintah dalam merealisaikan mobile government. Segala permasalahan negara dan tata kelola kepemerintahan dapat berjalan dengan baik dan dapat diselesaikan dengan efektif jika terdapat keseriusan pemerintah di dalamnya (Santoso, 2007). Lebih lanjut, 
penerapan mobile government pada Pemerintah Provinsi Jawa Barat memberikan kemudahan kepada masyarakat luas. Terdapat lima kemudahan dan keuntungan yang diperoleh, yaitu:

1) Informasi diperoleh dengan tepat waktu. Hal ini menjadi sangat krusial disaat negara dihadapkan pada kondisi yang darurat seperti pandemic Covid-19.

2) Masyarakat dapat menggunakan layanan public kapanpun dan tidak terbatas territorial.

3) Aksesibilitas yang tinggi terhadap pemanfaatan dan penggunaan informasi public baik oleh masyarakat dan pemerintah.

4) Dapat memberikan pelayanan spesifik berdasarkan lokasi masyarakat sesuai dengan kebijakan yang berlaku.

5) Kemudahan dalam penyampaian permasalahan, kritik, aspirasi, dan keluhan daripada masyaarakat.

Transformasi dalam melakukan pelayanan publik menjadi perubahan yang tidak terjadi secara gradual. Diawali dengan fase traditional services yang dicirikan sebagai pelayanan tatap muka pada lokasi yang tetap. Pada tahap kedua electronic service, pemerintah mulai membangun dan menggunakan fasiltas internet sebagai pengembangan internal dan penyampaian informasi pada public. Lalu, sampailah pada fase mobile service dengan memanfaatkan beragam teknologi yang tersedia dengan mengintegrasikan beragam pelayanan public di dalamnya.

\section{Kesimpulan}

Berdasarkan penelitian yang dilakukan, diperoleh bahwa pemanfaatan peluang digital pada sektor pemerintahan yang dikorelasikan dengan mobile governmet dilaksanakan dengan baik. Pemerintah Provinsi Jawa Barat telah membuat aplikasi-aplikasi seperti PIKOBAR, Sapawarga, K-Mob, Si Votun Jabar, dan Sambara yang berbasis mobile apps. Mobile government memberikan nilai tambah pada penerapan konsep egovernment dengan menyatukan beragam fasilitas pelayanan publik. Masyarakat sebagai penerima pelayan public mendapatkan kemudahan dalam mengakses informasi-informasi publik yang diperlukan. Hingga saat ini Pemerintah Provinsi Jawa Barat terus melakukan pembaharuan melalui pengembangan performa aplikasi dan perancangan aplikasi lainnya sebagai wujud pelaksanaan good governance.

\section{Referensi}

Abu Tair, H. Y. A., \& Abu-Shanab, E. A. (2014). Mobile Government Services. International Journal of Technology Diffusion, 5(1), 1725.

https://doi.org/10.4018/ijtd.20 14010102

Anggara, S. (2016). Ilmu Adminsitrasi Negara. Bandung: CV PUSTAKA SETIA.

Febriani, R. (2016). Gambaran eGovernment di Indonesia yang Bersistem Desentralisasi Ditinjau dari Performa Situs Web Pemerintah Daerah. Nirmana, 16(1), 64-72. https://doi.org/10.9744/nirman a.16.1.64-72

Hadiana, A. I. D., \& Renaldi, F. (2018). Penerapan Mobile Government Pada Monitoring Aktigitas Aparatur Sipil Negara Di Dinas 
Komunikasi dan Informatika Kabupaten Bandung Barat. JUMANJI Uurnal Masyarakat Informatika Unjani), 2(2), 32-39.

Handayani, F. A., \& Nur, M. I. (2019). Implementasi Good Governance Di Indonesia. Publica: Jurnal Pemikiran Administrasi Negara, 11(1), $1-11$. https://doi.org/10.15575/jpan.v $11 \mathrm{i} 1.7631$

Hardi, R., \& Gohwong, S. (2020). EGovernment Based Urban Governance on the Smart City Program in Makassar, Indonesia. Journal of Contemporary Governance and Public Policy, 1(1), 12-17. https://doi.org/10.46507/jcgpp. v1i1.10

Haryanto, A. T. (2020). Riset: Ada 175,2 Juta Pengguna Internet di Indonesia. DetikInet. https://inet.detik.com/cyberlife/ d-4907674/riset-ada-1752-jutapengguna-internet-di-indonesia

Hermansyah. (2020). Ridwan Kamil Launching Aplikasi PIKOBAR: Warga Jabar Bisa Update Kasus, Cari Informasi, hingga Donasi lewat Gawai. Jabarprov.Go.Id. http://humas.jabarprov.go.id/ri dwan-kamil-launching-aplikasipikobar-warga-jabar-bisaupdate-kasus-cari-informasihingga-donasi-lewatgawai/3083

Indonesiabaik.ic. (2018). 66,3\% masyarakat Indonesia Memiliki Smartphone. Riset Siap Bangun Negara.

http://indonesiabaik.id/infografi s/663-masyarakat-indonesiamemiliki-smartphone-8

Jabarprov.go.id. (2021). Si Votun Jabar, Aplikasi Keterbukaan Informasi Bagi Tunanetra. Jabarprov.Go.Id. https://jabarprov.go.id/index.ph p/news/41060/2021/01/25/SiVotun-Jabar-Aplikasi-

Keterbukaan-Informasi-BagiTunanetra

Mardiasmo. (2018). Akuntansi Sektor Publik (I). Jakarta: Penerbit ANDI.

menpan.go.id. (2020). Hasil Survei $P B B$, "e-Government" Indonesia Naik Peringkat. Menpan.Go.Id. https://menpan.go.id/site/berit a-terkini/hasil-survei-pbb-egovernment-indonesia-naikperingkat

Pamungkas, W. W. (2020). Pakai Aplikasi Sapawarga, Ridwan Kamil Minta 58.000 Ketua RW Aktif Sosialisasi $3 M$. Bandung.Bisnis.Com.

https://bandung.bisnis.com/rea d/20201213/549/1330189/pak ai-aplikasi-sapawarga-ridwankamil-minta-58000-ketua-rwaktif-sosialisasi-3m

Pratama, D., Hakim, D. A., Prasetya, Y., Febriandika, N. R., Trijati, M., \& Fadlilah, U. (2016). Rancang Bangun Alat dan Aplikasi untuk Para Penyandang Tunanetra Berbasis Smartphone Android. Khazanah Informatika: Jurnal Ilmu Komputer Dan Informatika, 2(1), 14. https://doi.org/10.23917/khif.v 2i1.1927

Santoso, A. (2007). Faktor-Faktor Politik, Administrasi dan Budaya dalam Masalah Korupsi di Indonesia. In JKAP Uurnal Kebijakan dan Administrasi Publik) (Vol. 11, Issue 1, pp. 8798). https://doi.org/10.22146/jkap.8 555

Savitri, A. (2019). Revolusi Industri 4.0 (III). Yogyakarta: Penerbit Genesis. 